\section{Percepção de riscos no trabalho rural em uma região agrícola do Estado do Rio de Janeiro, Brasil: agrotóxicos, saúde e ambiente}

\author{
Risk perception related to work in a rural \\ community of Rio de Janeiro State, Brazil: \\ pesticides, health, and environment
}

Frederico Peres 1

Brani Rozemberg 2

Sérgio Roberto de Lucca ${ }^{3}$

\section{Introdução}

The present study applies the risk perception analytical methodology based on rapid surveys. It took place in the micro-basin of the São Lourenço Creek in Nova Friburgo, Rio de Janeiro State, Brazil. The methodological approach was based on participatory observation, semi-structured interviews with 24 key informants selected among local farmers $(N=120)$, and evaluation of local work processes. Field data analysis revealed some issues related to the risk perception profile in the study population, including the development of defensive strategies to deal with work hazards, the importance of communication in developing workers' risk perceptions, the subjective responses to potentially hazardous situations, and the role of individual risk perception as a determinant of human exposure to pesticides. The results evoked the importance of systematically incorporating risk perception analyses into intervention strategies, especially in educational risk communication campaigns.

Pesticides; Occupational Health; Risk; Rural Population
A crescente subordinação do processo de produção agrícola à economia de mercado determina a constituição de uma situação paradoxal onde a incorporação tecnológica, por um lado, possibilita o aumento e a diversificação da produção e, por outro, está associada ao surgimento de novas injúrias à saúde e à segurança daqueles que utilizam tais tecnologias.

Não se pode negar o crescimento, em termos de produtividade, proporcionado pela difusão de tais tecnologias no campo. Pimentel et al. 1 estimam que para cada dólar americano gasto em agrotóxicos, se ganha em torno de quatro com a proteção das lavouras e o valor que se agrega ao produto comercializado. Entretanto, esta difusão maciça constitui-se como um dos principais desafios à saúde pública no meio rural, sobretudo no que concerne ao impacto ambiental e à saúde do homem do campo 2,3 .

Dentre o arsenal tecnológico oferecido, os agrotóxicos se destacam como a alternativa mais acessível para o aumento da produtividade agrícola, ou mesmo para a garantia da produção. O Brasil é o quarto maior consumidor individual de agrotóxicos no mundo (Food and Agriculture Organization of the United Nations. http:/ / faostat.fao.org/faostat/collections?subset=agriculture, acessado em 15/Set/2004). Ainda de acordo com estimativas da FAO (Food and 
Agriculture Organization), somente no ano de 2001 foram consumidas no país 328.413 toneladas de agrotóxicos.

Estima-se que dois terços da população do país estão expostos, em diferentes níveis, aos efeitos nocivos desses agentes químicos, seja em função do consumo de alimentos contaminados, do uso de agrotóxicos para o combate de vetores de doenças infecto-contagiosas ou pela atividade laboral. Mas nenhum grupo populacional brasileiro é tão vulnerável a esses produtos quanto os trabalhadores rurais 4 . Entender a dimensão do problema para este grupo - com vistas à elaboração de estratégias de intervenção/mitigadoras - é um dos grandes desafios da parcela do setor saúde voltada à assistência e à vigilância das populações rurais.

A grande maioria dos estudos acerca da contaminação rural por agrotóxicos no Brasil não leva em consideração a dimensão social do risco representado pela exposição a esses produtos, focalizando suas investigações nas análises técnicas do risco, baseadas nos conhecimentos da toxicologia. Com base neste ponto de vista, a população (ou grupos populacionais específicos) exposta(os) aos agrotóxicos é(são) avaliada(os) por parâmetros equânimes (indicadores de efeito, dados sobre a contaminação ambiental, identificação das vias de intoxicação etc.).

Entretanto, as pessoas tendem a responder de maneiras diferentes frente aos perigos a que estão expostas. Este fenômeno está relacionado tanto com a estimativa pessoal das decorrências de um determinado evento danoso, quanto com o sentimento de controle (ou de estar no controle) 5 .

Da mesma forma, um engenheiro de segurança de um planta industrial tem uma visão / interpretação dos perigos oriundos do funcionamento da mesma diferente daquela da população residente às áreas circunvizinhas, bem como um agrônomo pode dimensionar um determinado risco de maneira oposta a um trabalhador rural 6 . Ao deparar-se frente a um determinado perigo, advindo do processo de trabalho, um agricultor responde de acordo com as suas crenças, experiências, imagens e informações construídas ao longo de sua trajetória de vida. A percepção do perigo é fruto da associação de todos estes determinantes com o cenário em que se encontra, no momento 7. Assim, não há como conceber uma avaliação de riscos desconexa das crenças, interpretações e reações dos sujeitos envolvidos 8 .

\section{O que é percepção de risco?}

Segundo Wiedemann 7 (p. 3), a percepção de riscos é definida como sendo a "habilidade de interpretar uma situação de potencial dano à saúde ou à vida da pessoa, ou de terceiros, baseada em experiências anteriores e sua extrapolação para um momento futuro, habilidade esta que varia de uma vaga opinião a uma firme convicção". Para o autor, a percepção de riscos é baseada principalmente em imagens e crenças e tem raízes, em uma menor extensão, em alguma experiência anterior como, por exemplo, acidentes que um motorista já teve, o conhecimento de desastres anteriores e a relação com informações sobre a probabilidade de um desastre ocorrer.

Os estudos de percepção de riscos surgem a partir da década de 1970/1980 como um importante contraponto à perspectiva utilitarista das análises técnicas de risco, baseada nos saberes das engenharias, toxicologia, economia e ciências atuariais, e que não contemplava as crenças, receios e inquietações das comunidades envolvidas 9,10,11. Emergem e se consolidam, em uma área do saber cientificamente organizada, com o intuito de desvelar as razões que acompanhavam as reações negativas do público leigo frente ao advento de uma nova tecnologia, mesmo que com o aval dos especialistas técnicos 12,13,14.

O ponto de partida de qualquer estudo de percepção de riscos é o quanto difere a interpretação de uma pessoa "leiga" - entendida aqui como aquela que não adquiriu conhecimentos específicos sobre o objeto em questão, ao longo se sua trajetória de vida - para um determinado perigo, da interpretação do mesmo por parte de um "especialista" 7. A percepção de riscos da população é, geralmente, bastante distinta daquela dos especialistas, sobretudo cientistas 10. Suas interpretações baseiam-se muito mais em suas próprias crenças e convicções do que em fatos e dados empíricos, elementos que constituem a base de construção da percepção de riscos de técnicos e cientistas 15 .

Para Sjöberg \& Fromm 16, a população em geral tende a perceber mais os riscos que os benefícios de uma determinada tecnologia. De acordo com os autores, essa tendência tem sido encontrada em diversos estudos sobre percepção de riscos e benefícios, sobretudo aqueles relacionados com a implementação de novas tecnologias, onde se evidencia o ceticismo do público, geralmente em face aos empecilhos relacionados a estas tecnologias. 
Experiência, informação e "background" cultural formam uma tríade indissociável de determinantes da percepção de riscos, embora estes não esgotem os fatores relacionados com a construção da percepção de riscos em populações e/ou grupos populacionais específicos. Outros fatores, como o grau de escolaridade e a especificidade de tarefas realizadas, também contribuem para a base de sustentação da percepção de riscos das pessoas.

Sjöberg \& Drottz-Sjöberg 17, em estudo sobre a percepção de riscos de trabalhadores de usinas nucleares européias e norte-americanas, analisaram a relação entre o conhecimento (formal e prático - este último entendido como aquele advindo do desenvolvimento cotidiano das tarefas realizadas por um trabalhador) e a percepção de riscos ambientais e ocupacionais. Os resultados desvelaram uma situação em que os trabalhadores que realizavam tarefas mais específicas, mas que tinham menor grau de escolaridade, tinham uma percepção de riscos menos acurada que aqueles que desempenhavam tarefas que requisitavam menor conhecimento prático, mas que, entretanto, possuíam maior grau de escolaridade 17 .

Um dos principais obstáculos à realização de estudos de percepção de riscos é o (curto) tempo disponível em pesquisas de campo, que incluem, geralmente, longas viagens, requisitando a permanência no local de estudo por tempo indeterminado, incompatível com as agendas da grande maioria dos pesquisadores, sejam estes do setor público ou da iniciativa privada 18 .

Dentro desse cenário, as metodologias qualitativas de investigação por meio de diagnóstico rápido (ou estudos tipo RAP, do inglês Rapid Assessment Procedures) aparecem como solução ao dilema que se apresenta. Estas metodologias possibilitam a incorporação de informações subjetivas, crenças e percepções das populações locais em projetos de extensão e pesquisa, fato este impossível de se conseguir por meio de métodos quantitativos de larga escala. Mais importante: essas metodologias trazem o reconhecimento do fato de que os sujeitos possuem um conhecimento inestimável, indispensável à elaboração/execução de ações em nível local.

O presente estudo objetiva a análise da percepção de riscos de uma comunidade rural do Estado do Rio de Janeiro em sua relação com o trabalho local e o uso de produtos agrotóxicos no processo produtivo.

\section{Metodologia}

A região da Microbacia do Córrego do São Lourenço, Município de Nova Friburgo, Rio de Janeiro, Brasil, é o principal pólo produtor de olerícolas do Estado, com uma produção anual de 1.750 toneladas de tomate e 600 de couveflor, suas principais culturas de verão e inverno, respectivamente 19,20 .

Devido à intensa produtividade e às características do processo de produção adotado baseado no uso de agrotóxicos - entre outros determinantes, a região se caracteriza como uma das principais consumidoras desses agentes químicos no país, com uma média de $56,5 \mathrm{~kg}$ de agrotóxico por trabalhador por ano, valor este $76 \%$ maior que a média do Estado de São Paulo (a maior média nacional, com $31,1 \mathrm{~kg}$ ) e $1.822 \%$ maior que a média do Estado do Rio de Janeiro 20,21.

A população da região é constituída de aproximadamente 650 pessoas, divididas em 120 pequenas propriedades (em média de um a dois hectares). A faixa etária média da população é de 30 a 35 anos e cerca de $30 \%$ são analfabetos 20 .

A primeira etapa da pesquisa de campo (fase exploratória) compreendeu o diagnóstico inicial da situação local, baseado em observação participante de características do ambiente, diversidade populacional, relações sociais, processos de trabalho e relações de poder em nível local, entre outros aspectos. Adicionalmente, foram realizadas, nesta etapa, cinco entrevistas abertas com informantes-chave identificados dentre a população local, com o objetivo de subsidiar a definição de categorias analíticas e informantes-chave a serem incluídos na etapa principal de levantamento de dados/ entrevistas.

Após a realização da etapa exploratória da pesquisa foi possível definir as categorias empíricas que seriam adotadas, posteriormente, no processo de coleta de dados. Estas se basearam nas impressões, inquietações, anseios e medos apresentados pelos informantes-chave durante as entrevistas realizadas naquela etapa, e acabaram por proporcionar uma maior abrangência à investigação que se fazia presente. Assim, definiu-se as seguintes categorias: percepção de riscos ambientais; percepção de riscos à saúde; e estratégias defensivas desenvolvidas frente aos riscos ocupacionais.

A partir da definição das categorias empíricas foi possível delinear uma estratégia de ação para a coleta de dados em campo, por meio da realização de entrevistas individuais semi-estruturadas. Foram definidos, ainda, quatro cri- 
térios para a seleção dos informantes-chave: antiguidade na região; produtividade de suas lavouras; ter vivenciado episódio de intoxicação (o próprio e/ou parente próximo); abandono da atividade agrícola em decorrência de episódio de intoxicação (do próprio e/ou de parente próximo).

Os informantes-chave foram selecionados entre os trabalhadores que compareceram ao posto de saúde local em dois dias do mês de outubro de 2002, ocasião na qual uma equipe de pesquisadores da Fundação Oswaldo Cruz (FIOCRUZ) estava realizando coletas de sangue para análise da exposição/contaminação por agrotóxicos. A amostra foi definida em função do número de trabalhadores que, voluntariamente, se apresentaram para a realização do exame (aproximadamente 50). Respeitou-se a proporção de homens e mulheres ocupados na lavoura (dois homens para cada mulher, aproximadamente) e os critérios previamente definidos. Assim, obteve-se uma amostra de 24 trabalhadores, sendo dezesseis homens e oito mulheres. Em média, esses informantes tinham 30-35 anos e o primário incompleto como grau de escolaridade.

As entrevistas, realizadas individualmente em ambiente reservado, foram gravadas em fita cassete, sendo transcritas na íntegra pelo entrevistador. Na análise, utilizou-se trechos das falas dos trabalhadores sem qualquer edição, excetuando inícios e finais de frases que fugiam ao assunto abordado (nos quais se utilizava três pontos ...- indicando continuidade). Eventuais erros gramaticais foram registrados em respeito à fidedignidade das informações transcritas.

Utilizou-se para a análise das entrevistas transcritas técnicas de interpretação de discurso, por meio da categorização dos conteúdos, identificação de possíveis recorrências e análise dos significados, numa perspectiva interpretativa baseada na Abordagem Psicodinâmica do Trabalho de Christophe Dejours et al. 22 e no modelo explicativo de Arthur Kleinman 23.

\section{Resultados e discussão}

A análise dos dados de campo desvelou uma série de peculiaridades relativas à percepção de riscos dos agricultores entrevistados, sobretudo aquela relacionada ao uso de agrotóxicos no processo produtivo. Os principais pontos que aqui serão destacados são a percepção de riscos ambientais, a percepção de riscos à saúde e as estratégias defensivas elaboradas frente aos riscos oriundos do processo de trabalho.

\section{Percepção de riscos ambientais}

O principal risco ambiental relatado nas entrevistas foi a contaminação dos rios, seguida pela contaminação do solo. Tal fato pode estar ligado à presença de um manancial hídrico de grande importância na região (o Córrego do São Lourenço, juntamente com outros córregos de nascente da região, forma o Rio Grande, principal manancial hídrico do Município de Nova Friburgo). Outro fato que pode ter influenciado esta percepção é a presença da equipe de pesquisadores da FIOCRUZ, ligada a um projeto integrado de pesquisa (Programa de Pesquisa $O$ Destino dos Agrotóxicos na Microbacia do Córrego do São Lourenço, Nova Friburgo, Rio de Janeiro) que, freqüentemente, realiza coletas de água para análise da contaminação por agrotóxicos em laboratório. Ao verem esses técnicos coletarem, ao longo do leito do rio, amostras de água, os trabalhadores tendem a associar tal ato, imediatamente, a algum problema na qualidade dessa água, uma vez que os técnicos dessa equipe são facilmente identificados com a questão saúde/agrotóxicos. Tal fato pode demonstrar a repercussão na percepção de riscos de comunidades atendidas por projetos de pesquisa.

A preocupação acerca do rio é tal, que foram relatadas diversas outras formas de agressão ao ambiente, conscientes, como sendo "preferíveis" em relação à contaminação do rio: “As embalagem, quando acaba o produto a pessoa bota no lixo, né? Tem o carro que pega. Nós faz isso pra evitar que contamina as água, né? As pessoa que tão lidando em vorta, né?" (agricultor, 62 anos).

"Não, eu acho que tem pobrema não [queimar a embalagem vazia]. Porque ali ela vai embora, né? É pior se jogasse dentro dum ri" (agricultora, 52 anos).

A análise dos dados de campo mostrou que os trabalhadores da região de estudo, assim como alguns técnicos com estes envolvidos, desconsideram uma importante fonte de contaminação ambiental, derivada da concentração atmosférica de agrotóxicos em regiões de produção rural muito intensa, como a região de estudo. Tal fato é particularmente evidenciado no período de inverno devido ao fenômeno da inversão térmica na região, que, por conta da massa de ar fria, impede a eliminação das partículas de agrotóxico em suspensão, aumentando a concentração atmosférica dessas substâncias. Atualmente, há uma equipe da FIOCRUZ estudando este fenômeno na região.

Outros fatores como o solo e os ventos também foram identificados: "O pobrema do vene- 
no é essas coisa, né? É prejudicial à saúde. E o ambiente também. O vento transmite mais, carrega muito longe, as vez tem que gente que tá surfatando longe demais e a gente sente o cheiro do veneno" (agricultor, 45 anos).

"São vários pobrema, né? É veneno, o nome já diz tudo. Tanto na pessoa que tá manuseando aqui na lavoura tanto na pessoa que vai consumir o produto, eu acho que é pobremático. Se você não usar de maneira correta você vai tá contaminando o solo" (agricultor, 38 anos).

Alguns trabalhadores identificam como uma situação "caótica” aquela vivenciada por eles no campo em relação às pragas que atingem suas lavouras. Para estes trabalhadores, o uso indiscriminado de agrotóxicos na região levou a uma situação de descontrole frente às pragas que hoje são observadas: "O problema é muito sério de usar o agrotóxico. É muito sério mesmo. A gente foi criando uma resistência e hoje tem mais tipo de pragas do que se tinha anteriormente. Nos anos atrás que não se usava agrotóxico. Em vez de diminuir, elas [as pragas] tá aumentando" (agricultora, 37 anos). "Os inseto tá muito aumentado. Parece que quanto mais veneno existe mais o inseto aumenta" (agricultor, 62 anos).

Uma agricultora chega a relacionar este "caos ambiental" às doenças dos seres humanos que surgiram nos últimos 30 anos, fazendo ainda uma associação entre os medicamentos utilizados no combate a estas doenças e o uso de agrotóxicos: "Há trinta anos atrás não havia o câncer, não havia a AIDS, não havia uma doença chamada Lupus, não tinha vários tipos de doença. Hoje em dia o que mais tem é AIDS, câncer. Você vê o que tem nas pessoa e é o que tem nas pranta. As pranta é igual as pessoa. Você pode conversar com as pranta que elas te entende. Agora, muitas pessoas tão doente precisam de um remédio. A lavoura precisa do remédio pra você pode colher" (agricultora, 31 anos).

Em trabalhos anteriores 20,21 discutiu-se sobre os determinantes que levam os trabalhadores a denominarem os agrotóxicos ora veneno, ora remédio. Estes determinantes, relacionados à vivência de casos de intoxicação e às estratégias defensivas desenvolvidas, condicionam a percepção de risco dos trabalhadores em relação aos efeitos nocivos do uso de agrotóxicos na lavoura 4.

\section{Percepção de riscos à saúde}

Com a análise dos dados de campo foi possível observar que os problemas de saúde relacionados aos agrotóxicos pelos produtores estão principalmente ligados aos sintomas/episó- dios de intoxicação aguda (aquela que é mais aparente, pois geralmente se traduz num quadro de "pane" do sistema nervoso) e aos sintomas "visíveis" da contaminação humana por agrotóxicos (problemas de pele, problemas nos olhos, alergias etc.).

O problema de saúde/sintoma mais relacionado aos agrotóxicos pelos produtores entrevistados foi “dor de cabeça”. Embora possam ter uma série de origens orgânicas, as dores de cabeça são freqüentemente associadas ao uso de agrotóxicos, muito provavelmente por serem estas um sintoma alerta do organismo, que geralmente acomete o trabalhador logo após um evento no qual este tenha se exposto a uma elevada concentração de agrotóxicos. Assim, as dores de cabeça são facilmente identificadas como um problema de saúde decorrente do uso/manipulação dos agrotóxicos, tanto pelo fato de terem presenciado (ou experimentado) eventos de intoxicação aguda, que encerram uma sintomatologia bastante característica, quanto pelo fato de, ao final de uma longa jornada de trabalho com agrotóxicos, observarem o surgimento destas dores de cabeça.

Outros sintomas relacionados aos agrotóxicos pelos produtores também traduzem um quadro comum aos episódios de intoxicação aguda: desorientação (desmaios, "zonzeira”, tonteira); convulsões (os "nervos" ou sistema nervoso); náuseas; falta de ar; e vômitos (talvez o quadro mais marcante para quem assiste a um episódio de intoxicação aguda aos agrotóxicos, provocado pela presença de substâncias eméticas que provocam vômito - nos agrotóxicos, com a finalidade de minimizar o impacto da ingestão acidental ou intencional - desses produtos).

Tal fato encontra suas bases na influência da experiência concreta (a realidade vivida, vivenciada, visualizada pelo trabalhador dia-apósdia) na construção de seu pensamento, como pode-se observar nas falas a seguir: "Rapaz, eu cheguei a uma conclusão que eu vou te falar uma coisa, trabalhando com o veneno me intucicou de uma maneira que eu vou dizer uma coisa, não teve jeito. Me dava dor de cabeça, ficava com as perna doendo também, tonteira, vista escura, foi indo até que eu tive quase um ano em cima de uma cama" (agricultor, 55 anos).

"Eu sentia só essa tonteira, esse negócio de veneno, porque eu puxava mangueira, e de repente eu baixava assim puxando, aí eu levantava e ficava tonta. Com dor de cabeça e vômito" (agricultora, 28 anos).

Dos 24 entrevistados, apenas um reconheceu que aqueles sintomas observados/sentidos representavam um perigo para a sua saúde. $\mathrm{Pa}-$ ra os demais, o risco era tangível somente às 
outras pessoas, visto que, segundo os relatos, eles eram "fortes" e que o veneno não lhes causava nenhum "problema sério" (tal fato será melhor discutido na seção sobre estratégias defensivas).

De acordo com Tucker \& Napier 24 , pelo fato de os pequenos produtores rurais determinarem o tipo de proteção química usada em seus sistemas de produção, eles costumam enxergar o uso de agrotóxicos como voluntário e familiar (no sentido de ser comum ao seu cotidiano), especialmente devido à extensa experiência que adquiriram ao longos dos anos com o intenso e massivo uso desses produtos. Dado a esta familiaridade, os autores sugerem que fazendeiros tendem a atribuir níveis relativamente baixos de risco ao regime de uso desses agentes.

A análise dos dados de campo possibilitou um achado semelhante ao dos autores acima, conforme é observado nos seguintes depoimentos: “O perigo é não saber usar o agrotóxico, começa por aí. É o mais perigoso que existe. É um perigo porque muita gente abusa, coloca de qualquer maneira, perto da casa onde ele mora, as vez o cara tá purvizando e tem criança do lado, a gente cansa de ver aí criança pequenininha, as vez sem camisa, puxando mangueira, outra tá na frente e o pai tá purvizando atrás" (agricultor, 45 anos).

"Eles fala muito que tem pobrema esse negócio de sulfatação, de trabalhar com o veneno e sem a máscara, sem a proteção. O patrão mesmo fala que e gente fica ruim, fica doente, e depois não tem mesmo como a gente trabalhar, se precisar. Aí tem que ficar em cima de uma cama. Mas eu num sei não, eu nunca senti nada, então não sei não" (agricultora, 28 anos).

“Olha, bem (o agrotóxico) num faz, mas muito mal também não deve fazer, porque pelos anos que a gente já vive nisso, nunca deu pobrema" (agricultora, 31 anos).

Dois aspectos podem ser observados neste momento. O primeiro está relacionado com o fato de os agricultores imputarem o risco do agrotóxico a um descuido ou a uma imprudência de determinados agricultores, que não estariam "preparados" para lidar com esses produtos. Tal fato tem origem em uma das mais perversas práticas exploratórias observadas no meio rural: a culpabilização do agricultor pelos riscos do uso dos agrotóxicos, presente nas falas de técnicos de extensão e pesquisa rural, rótulos de produtos agrotóxicos, "folders" informativos e cartilhas, conforme já mapeado em outros estudos realizados na mesma área 2,20,21.

O lado mais perverso dessa prática de culpabilização, presente tanto no material infor- mativo quanto nas falas dos profissionais, é a construção de uma auto-imagem negativa por parte dos trabalhadores rurais: "O que falta para o produtor é mais conscientização. Porque ele acha que, muita das vez, um produto marcado para botar $20 \mathrm{ml}$ e outro marcado pra botar 300 , e ele acha que o de 20 não faz efeito, e na verdade faz o mesmo efeito, porque é um produto mais concentrado" (agricultor, 38 anos).

"Eu acho que o povo é cabeça-dura, né? A gente passa pra eles e eles não quer acreditar. As pessoa fala e eles [os trabalhadores] não entende. Aprendeu daquele jeito e acha que tem que ser sempre, só daquele jeito" (agricultor, 27 anos).

“A gente tenta botar na cabeça deles e eles acha que não, é daquele jeito que tem que funcionar. E aí fica difícil. Eu acho que num falta orientação não, eu acho que é cabeça-dura mermo" (agricultor, 45 anos).

"Tem gente que é um pouco meio teimoso. As vez o patrão passa como usar de maneira assim e ele não respeita. Tem que ficar em cima e falar 'você tem que fazer assim se não você vai se dar mal" (agricultor, 62 anos).

O problema dos agrotóxicos passa a ser, então, o próprio trabalhador. A indústria e o comércio, por meio de suas práticas comunicativas, delegam o problema ao trabalhador que, por sua vez, é levado a crer nesta ilusão e, reforçado pelas falas dos profissionais que os visitam em campo, magnifica o problema, assumindo que ele mesmo é o problema. Tal situação, extremamente confortável para a indústria/comércio, é brutalmente prejudicial para o trabalhador, que vê suas crenças e suas práticas de trabalho destroçadas por um saber etnocêntrico, que se faz referência pelo poder do conhecimento formal e da ciência lato sensu.

\section{Estratégias defensivas}

Quando um trabalhador está operando frente a uma situação de trabalho potencialmente danosa à sua saúde, observa-se freqüentemente uma certa atitude de desprezo em relação ao risco ali presente. No caso da construção civil, por exemplo, é possível observar trabalhadores escalando andaimes sem o uso de cintos de segurança, como forma de demonstrar aos colegas sua bravura, virilidade. Muitas vezes, estes trabalhadores costumam classificar os outros, aqueles que seguem à risca as normas de segurança e saúde no trabalho, como "afeminados", "mocinhas", "delicados" e "fracos".

Para Dejours 25, essa atitude de desprezo ao risco não pode ser tomada ao pé da letra, como se o trabalhador desconhecesse por completo os riscos inerentes àquela atividade. Muito pe- 
lo contrário, tal estratégia suscita o pleno conhecimento do perigo, onde o trabalhador acrescenta ao risco inerente ao processo de trabalho o seu próprio risco, como forma de minimizar ou simplesmente negar o outro, numa estratégia que o autor classifica como ideologia defensiva. A principal função desta ideologia defensiva seria propiciar ao trabalhador a sobrevivência em um ambiente/processo de trabalho injurioso, por meio da constituição de um valor simbólico onde o trabalhador domina o perigo, e não vice-versa. Além disso, segundo o autor 25 (p. 32), " a consciência aguda do risco do trabalho, mesmo sem envolvimentos emocionais, obrigaria o trabalhador a tomar tantas precauções individuais que ele se tornaria ineficaz do ponto de vista da produtividade".

No caso dos trabalhadores rurais, é comum observar, em seus relatos e falas, a alusão a determinadas pessoas que são "fracas para o veneno”, em contraposição ao próprio narrador que, freqüentemente, faz a ressalva de que ele está "acostumado a lidar com o veneno" ou "preparado" para aquela situação, como é possível observar na fala deste agricultor: "Eu acho que pode acontecer comigo. No decorrer, as vez, num sei, né? A gente pode até ficar mais fraco. Eu acho que tem pessoa fraca pro veneno. Tem gente que não pode nem ver o cheiro. Já teve gente de trabalhar em casa de veneno [casa de comércio de agrotóxicos], tava trabalhando lá e teve que parar. Só pelo cheiro de trabalhar ali ela não consegue trabalhar. Tem gente que se passar no caminho e tiver purvizando ele já passa mal, sento o estâmago ruim, ou a cabeça começa a doer" (agricultor, 45 anos).

"Olha, eu trabalho com veneno tem mais de trinta, trinta e cinco anos e nunquinha tive pobrema nenhum. Agora meu irmão que é mais moço do que eu já teve vez de ter que ir pro hospital, tava intucicado. É por isso que eu te digo que tem gente que é fraca pro remédio" (agricultor, 68 anos).

Em estudos anteriores, realizados na mesma região 2,20,21, foi possível observar que os relatos de intoxicação eram sempre na terceira pessoa: fulano já passou mal, sicrano não pode nem chegar perto do veneno etc. No desenvolvimento desses trabalhos, constatou-se que aqueles trabalhadores que negavam já ter se sentido mal, eram apontados por outros como pessoas que já haviam experimentado os efeitos nocivos dos agrotóxicos, o que reforça a teoria da construção de estratégias defensivas (no caso, a negação do risco ou da relação entre causa e efeito) por parte deste grupo 22 .

Como visto anteriormente, apenas um entre os 24 entrevistados afirmou ter tido proble- mas sérios de saúde devido ao uso de agrotóxicos. Justamente o único que, entre os 24 , abandonou a atividade agrícola e hoje trabalha para a prefeitura, na zona urbana do município. Para este trabalhador, a estratégia defensiva não mais funcionou e, assim, se viu obrigado a abandonar aquela atividade de trabalho. Todos os demais trabalhadores entrevistados minimizaram a ocorrência dos sintomas, como sendo comuns e não diretamente relacionados com o uso de agrotóxicos na lavoura. Eles continuam a trabalhar na lavoura lidando, quase que diariamente, com agrotóxicos. Nestes trabalhadores, as estratégias defensivas estão bem sólidas e mesmo quando algum deles relata qualquer sinal de alerta do organismo frente à exposição aos agrotóxicos, ele minimiza a importância do evento:

“Às vezes, depois de uma hora ou duas de trabalho com defensivo, às vezes eu apresento uma dorzinha de cabeça, a gente sente que foi provocado por aquilo. Dá dor de cabeça, às vezes sente o estômago enjoado, então isso depende muito do produto" (agricultor, 38 anos).

O agrotóxico aqui é chamado de defensivo. A dor de cabeça vira uma "dorzinha”. E, assim, ele torna possível sua permanência num processo de trabalho reconhecidamente injurioso.

O processo e as condições de trabalho são, para Dejours 25, determinantes da percepção de riscos dos trabalhadores e, em última instância, principais responsáveis pela construção do desprazer relacionado ao trabalho. São, ainda, os fatores primariamente apontados como "perigosos" pelos trabalhadores. Em uma indústria, por exemplo, fica muito evidente a relação entre as condições de trabalho e o risco ali presente. O risco, nestes casos, é sempre relacionado ao corpo do indivíduo (quedas, choques, queimaduras, fraturas etc.). No caso do trabalhador rural, não há uma clara associação, por parte do trabalhador, entre as condições de trabalho e a percepção de riscos. O processo de pulverização, por exemplo, não causa desconfortos excessivos ao trabalhador, não o obriga a esforços físicos acentuados, não apresenta "perigos visíveis”. Mas o perigo está lá, no bico do pulverizador carregado pelo trabalhador, na mangueira puxada por sua esposa, na nuvem de agrotóxico formada, que é respirada por ambos.

Na grande maioria das vezes, os trabalhadores reconhecem aquela atividade como perigosa, embora desconheçam os limites deste risco em função da invisibilidade do problema. Para Dejours 25 (p. 33) “o medo relativo ao risco pode ficar sensivelmente amplificado pelo desconhecimento dos limites deste risco, ou pela ig- 
norância dos métodos de prevenção eficazes. Além de ser um coeficiente de multiplicação do medo, a ignorância aumenta também o custo mental ou psíquico do trabalho".

\section{Considerações finais}

Por entender que o conhecimento do homem do campo deve ser respeitado e levado em consideração em toda e qualquer estratégia (intervenção, educação, mitigação de efeitos adversos à saúde e ao ambiente) a ser desenvolvida no meio rural, o presente trabalho objetivou a construção e a aplicação de uma abordagem teórico-metodológica da percepção de riscos, baseada em técnicas de diagnóstico rápido (RAP), adequada à realidade do trabalhador rural brasileiro e que privilegiasse seus saberes, valores e crenças, levando em consideração a percepção (no sentido mais amplo da palavra) dos indivíduos, comunidades e grupos populacionais envolvidos com os processos/situações potencialmente danosos.

Neste sentido, foi possível incorporar os conhecimentos aqui apresentados no âmbito de um programa integrado de avaliação e controle de agrotóxicos na região, tornando mais ágeis e objetivas as estratégias de intervenção que, desde 2003, vêm sendo desenvolvidas nessa região.

A análise dos resultados do estudo mostrou que a percepção de risco desse grupo populacional difere da avaliação de técnicos que prestam serviços a essas comunidades (agrônomos, engenheiros químicos, biólogos etc.) e, por esta razão, acabam por determinar o nãosucesso de uma série de estratégias de intervenção no meio rural. Ademais, estas ações extensionistas, freqüentemente elaboradas em

\section{Resumo}

O presente trabalho objetivou a aplicação de uma abordagem antropológica de diagnóstico rápido da percepção de riscos no trabalho rural. O estudo foi realizado na região da Microbacia do Córrego do São Lourenço, Nova Friburgo, Rio de Janeiro, Brasil. A metodologia aplicada esteve baseada em: observações participantes na localidade; entrevistas semi-estruturadas com 24 informantes-chave, selecionados entre os produtores rurais da região (aproximadamente 120); e avaliação do processo de trabalho local. A análise dos dados desvelou uma série de questões relacionadas com a percepção de riscos da população estudada, incluindo o desenvolvimento de estratégias de defesa frente aos perigos vivenciados no trabalho, a linguagem imperativa e colocando sobre o trabalhador rural a responsabilidade sobre sua situação de saúde e a qualidade do ambiente, acabam por criar distorções sérias, onde o trabalhador se vê como "ignorante", "burro", "despercebido das coisas" (auto-imagem negativa).

Os principais aspectos relacionados à percepção de riscos no trabalho rural são a minimização de riscos/negação do perigo e o desenvolvimento de estratégias defensivas - individuais e coletivas - pelos trabalhadores rurais, aspectos estes que encontram seus determinantes na organização do trabalho e na ação técnica voltada à extensão rural.

Se por um lado as estratégias defensivas aumentam a vulnerabilidade da população masculina (principalmente) no campo, elas tornam possível que este grupo suporte um processo de trabalho altamente injurioso e arriscado. E, por isto, não devem ser entendidas, apenas, como uma barreira a ser transposta, e sim como um determinante a ser levado em consideração em ações educativas e de comunicação de riscos.

Assim, os estudos de percepção de riscos devem ser incorporados intrinsecamente às estratégias educativas, de avaliação e comunicação de riscos. Por intermédio da fala e das representações que os indivíduos têm acerca de seu universo é possível articular a situação do sujeito no mundo, apontando sempre novos lugares de onde o sujeito pode responder aos demais. E, assim, torna-se possível explicar de que forma a experiência e o senso comum dos trabalhadores rurais se apropriam e dão sentido aos conceitos vindos das tecnologias agrícolas, ponto de partida para toda e qualquer estratégia educativa relacionada ao uso de agrotóxicos no meio rural. importância da comunicação na construção dos referenciais de risco entre os trabalhadores, as respostas subjetivas frente a situações de potencial dano à saúde e o papel da percepção individual e coletiva dos riscos na determinação da exposição a produtos químicos perigosos, sobretudo os agrotóxicos. Os resultados apontaram para a importância das análises de percepção de riscos no processo de construção de estratégias de intervenção no meio rural, sobretudo políticas e campanhas educativas e de comunicação de riscos.

Praguicidas; Saúde Ocupacional; Risco; População Rural 


\section{Colaboradores}

F. Peres participou do levantamento dos dados de campo, da redação e da revisão do artigo. B. Rozemberg e S. R. Lucca participaram da revisão do artigo.

\section{Referências}

1. Pimentel D, Acquay H, Biltonen M, Rice P, Silva $\mathrm{M}$, Nelson J, et al. Environmental and economic costs of pesticide use. Bioscience 1992; 42:750-60.

2. Moreira JC, Jacob SC, Peres F, Lima JS, Meyer A, Oliveira-Silva JJ, et al. Avaliação integrada do impacto do uso de agrotóxicos sobre a saúde humana em uma comunidade agrícola de Nova Friburgo/RJ. Ciênc Saúde Coletiva 2002; 7:299-311.

3. Yudelman M, Ratta A, Nygaard D. Pest management and food production looking to the future. Washington, DC: International Food Policy Research Institute; 1998. (Food, Agriculture and the Environment Discussion Paper 25).

4. Peres F, Moreira JC. É veneno ou é remédio? Agrotóxicos, saúde e ambiente. Rio de Janeiro: Editora Fiocruz; 2003.

5. Wolpert L. Risk. London: College University; 1996.

6. Kouabenan DR. Beliefs and the perception of risks and accidents. Risk Anal 1998; 18:243-52.

7. Wiedemann PM. Introduction risk perception and risk communication. Jülich: Programme Group Humans; Environment, Technology (MUT), Research Centre Jülich; 1993. (Arbeiten zur RiskoKommunikation 38).

8. Peres F. Onde mora o perigo? Percepção de riscos, ambiente e saúde. In: Minayo MCS, Miranda AC, organizadores. Saúde e ambiente sustentável: estreitando nós. Rio de Janeiro: Editora Fiocruz; 2002. p. 135-41.

9. Starr C. Social benefit versus tecnological risks. Science 1969; 165:1232-8.

10. Slovic P, Fischhoff B, Liechteisntein S. Rating the risks. Environment 1979; 21:36-9.

11. Gomez CM, Freitas CM. Análise de riscos tecnológicos na perspectiva das ciências sociais. Hist Ciênc Saúde Manguinhos 1997; 3:485-504.

12. Douglas M, Wildavsky A. Risk and culture - an essay on selection of technological and environmental dangers. Berkerley: University of California Press; 1982.

13. Otway HJ, Thomas K. Reflections on risk perception and policy. Risk Anal 1982; 2:69-82.
14. Otway HJ, Winterfeldt DV. Beyond acceptable risk: on the social accepetability of technologies. Policy Sci 1982; 14:247-56.

15. Slovic P. Perception of risk. Science 1987; 236:280-5.

16. Sjöberg L, Fromm J. Information technology risks as seen by the public. Risk Anal 2001; 21:427-41.

17. Sjöberg L, Drottz-Sjöberg BM. Knowledge and risk perception among nuclear power plant employees. Risk Anal 1991; 11:607-18.

18. Peres F. Onde mora o perigo? O processo de desenvolvimento de uma metodologia de diagnóstico rápido da percepção de risco no trabalho rural [Tese de Doutorado]. Campinas: Universidade Estadual de Campinas; 2003.

19. Empresa de Assistência Técnica e Extensão Rural. Programa Estadual de Desenvolvimento de Microbacias Hidrográficas - Nova Friburgo, Rio de Janeiro. Nova Friburgo: Empresa de Assistência Técnica e Extensão Rural; 2001.

20. Peres F. É veneno ou é remédio? Os desafios da comunicação rural sobre agrotóxicos [Dissertação de Mestrado]. Rio de Janeiro: Escola Nacional de Saúde Pública, Fundação de Saúde Pública; 1999.

21. Peres F, Rozemberg B, Alves SR, Moreira JC, Oliveira-Silva JJ. Comunicação relacionada ao uso de agrotóxicos em uma região agrícola do Estado do Rio de Janeiro. Rev Saúde Pública 2001; 35:564-70.

22. Dejours C. A loucura do trabalho. São Paulo: Cortez Editora; 1992.

23. Kleinman A. Patients and healers in the context of cultures. An exploration of borderland between Anthropology and Psychiatry. Berkeley/Los Angeles: University of California Press; 1980.

24. Tucker M, Napier TL. Determinants of perceived agricultural chemical risk in three watersheds in the Midwestern United States. J Rural Stud 2001; 17:219-33.

25. Dejours C, Abdouchely E, Jayet C. Psicodinâmica do trabalho. São Paulo: Atlas; 1994.

Recebido em 30/Nov/2004

Versão final reapresentada em 09/Mai/2005

Aprovado em 07/Jun/2005 